\title{
MUJERES, NACIONALISMO E ISLAMISMO EN PALESTINA. \\ ELEMENTOS PARA UNA LECTURA FEMINISTA DE LOS CONFLICTOS EN ORIENTE PRÓXIMO
}

\author{
Magaly THILL \\ Cátedra de Género. Universidad Rey Juan Carlos
}

Recibido: 28/08/2015

Aceptado: 06/09/2015

\section{Resumen}

Cuando la Resolución 1325 cumple quince años, el feminismo y el pacifismo necesitan repensar sus relaciones con los movimientos de mujeres en Oriente Próximo. Los conflictos que asolan la región, tienen un impacto de género que no puede estudiarse sin analizar el efecto del colonialismo y el imperialismo occidental en el constructo «mujer», y las relaciones que las principales fuerzas políticas mantienen con el feminismo y el movimiento de mujeres. El caso de Palestina ilustra cómo, en un contexto de ocupación militar prolongada, el colonialismo israelí, el nacionalismo palestino y el islamismo han utilizado el cuerpo de las mujeres para asentar sus respectivas retóricas de limpieza étnica, liberación nacional y autenticidad islámica. Se contextualiza la supuesta dicotomía entre feminismo secular y feminismo islámico, haciendo recomendaciones para evitar nuevos esencialismos identitarios. Entre resistencias y negociaciones, el movimiento feminista palestino apunta estrategias novedosas para abrir espacios de diálogo situado y equitativo.

Palabras clave: feminismo árabe, mujeres y paz, mujeres palestinas, conflicto israelopalestino, feminismo y mutliculturalismo.

\begin{abstract}
As UNSCR 1325 completes fifteen years, feminism and pacifism need to rethink their relationships with women's movement in the Middle East. The conflicts in the region have a gender impact that cannot be assessed without analysing the effects of
\end{abstract}


western colonialism and imperialism over the construct of «woman», as well as the relations between main political forces on one side and feminism and women's movement on the other one. The case of Palestine shows how in a context of prolonged military occupation, Israeli colonialism, Palestinian nationalism and Islamism have used women's bodies to develop their respective rhetoric of ethnic cleansing, national liberation and Islamic authenticity. The so-called dichotomy between secular feminism and Islamic feminism is contextualized, and some recommendations are put forward to avoid new identity essentialisms. In between resistances and negotiations, Palestinian feminist movement points out innovative strategies to allow situated and equitable dialogue.

Keywords: arab feminism, women and peace, palestinian women, israelí-palestinian conflicto, feminism and multiculturalism. 


\section{Introducción}

Desde el lanzamiento de la cruzada estadounidense contra Afganistán e Iraq hace más de una década, la situación en Oriente Próximo no ha dejado de degradarse. A la sombra de las invasiones militares, ocupaciones extranjeras, enfrentamientos intercomunitarios y guerras civiles, varios estados han implosionado, convirtiendo una de las regiones más estratégicas del mundo en un caos de pronóstico poco alentador. De acuerdo con los datos del International Institute for Strategic Studies ${ }^{1}$, Oriente Próximo sumó en el año 2014, más del $60 \%$ de las víctimas mortales ocasionadas en todos los conflictos armados del mundo, con 71.000 muertos en Siria, 18.000 en Irak, 12.000 en Sudán, 3.800 en Yemen y 2.500 en Palestina.

Las masacres civiles, atentados terroristas, desplazamientos forzados y demás vicisitudes que sufren las poblaciones de Oriente Próximo, no son ajenos a los intereses económicos y geoestratégicos de Occidente, a saber el control sobre el $65 \%$ de las reservas mundiales de petróleo y la seguridad de Israel (Gresh 2015). La conflictividad regional se suele atribuir a un conjunto de factores externos (la división colonial de la región en estados pluri-confesionales de difícil equilibrio, la agenda neoliberal impuesta a través de las instituciones financieras internacionales, la ocupación prolongada de Palestina y la invasión militar de Iraq) y de dinámicas de carácter endógeno (la corrupción y el autoritarismo de los dirigentes autóctonos, las desigualdades sociales y el empobrecimiento de las clases populares, la represión de las fuerzas de oposición, especialmente el islamismo, y el sometimiento por las armas de los levantamientos populares que estallaron en 2011).

Cuando se cumplen quince años de la Resolución 1325 de la ONU sobre Mujeres, Paz y Seguridad, cabe preguntarse cómo las mujeres árabes y sus organizaciones se ven afectadas por estos conflictos, cómo se posicionan ante ellos y cómo contribuyen a prevenir o resolverlos. Para ello, es necesario

1. Ver: International Institute for Strategic Studies. Armed Conflicts Database. En: https:// acd.iiss.org/ 
analizar el contexto en el que actúan, las fuerzas patriarcales con las que lidian y las características del movimiento feminista autóctono.

Ante la magnitud del reto, este artículo se limitará a aportar una serie de datos y reflexiones que faciliten una lectura feminista de la situación actual en Oriente Próximo. Asimismo, se centrará en un conflicto geográficamente circunscrito, el israelo-palestino, que debido a su excepcional duración, permitirá valorar los efectos a largo plazo de las guerras de la región. Asimismo, en Palestina, están convergiendo dos fenómenos aparentemente opuestos: por un lado una reafirmación nacional en torno a la identidad árabo-musulmana frente al ocupante israelí, y, por otro, unas relaciones culturales sostenidas con Occidente a través de la diáspora palestina y la cooperación internacional. Esta idiosincrasia será de gran utilidad para apreciar las interacciones entre el movimiento de mujeres autóctonas y los postulados tanto del feminismo ilustrado como del feminismo poscolonial procedente del pensamiento posmoderno.

\section{El género del conflicto armado y la violencia sexual como arma de guerra}

Es una idea avalada internacionalmente que los conflictos suelen exacerbar las desigualdades de género y exponer a las mujeres a situaciones de mayor vulnerabilidad. Varios informes han estudiado el impacto de género del conflicto israelo-palestino, demostrando que la ocupación colonial y las operaciones militares israelíes vulneran gravemente los derechos humanos de las mujeres, especialmente en la Franja de Gaza². En una sociedad asediada por tierra, mar y aire, donde el empleo femenino es muy inferior al masculino ${ }^{3}$, las palestinas sufren los efectos de la pobreza debiendo ingeniárselas para alimentar a sus familias. Si enviudan, esta situación se torna insostenible. Dado que su existencia transcurre en gran parte entre las paredes de sus hogares, las mujeres se ven también gravemente afectadas por las demoliciones de casas. Tan sólo en Gaza, el ataque israelí del verano 2014 arrasó más de dieciocho mil viviendas que siguen hoy en día sin reconstruir.

2. Por ejemplo: Amnesty International. Conflict, Occupation and Patriarchy: Women Carry the Burden. 2005; Euromediterranean Human Rights Network. Palestinian women's rights in the relations between EU and Israel and EU-Palestinian Authority. 2014; World Bank, Checkpoints and Barriers: Searching for Livelihoods in the West Bank and Gaza. Gender Dimensions of Economic Collapse. 2010.

3. En 2012, la tasa de actividad de los hombres (69,1\%) era cuatro veces más importante que la femenina $(17,4 \%)$, y el desempleo entre mujeres $(32,9 \%)$ era más alto que entre los hombres (20,5\%) (Palestinian Central Bureau of Statistics 2013). 
Asimismo, por razones atribuibles a las normas de género vigentes en la región, el Muro del Apartheid y otros obstáculos físicos como son los roadblocks (cortes de carreta con bloques, piedras o zanjas) y los checkpoints (puestos de control militares israelíes) restringen especialmente la movilidad de las mujeres, quienes a menudo prefieren renunciar a su derecho a la salud o a la educación antes que someterse a desplazamientos costosos, arriesgados y vejatorios. La denegación por Israel de la reunificación familiar y la prohibición de los enlaces matrimoniales entre palestinos israelíes y ciudadanos de la Autoridad Palestina (AP) quebrantan el derecho a la vida familiar de las mujeres y las obligan a vivir escondidas por temor a ser arrestadas por la policía israelí. Otro colectivo de mujeres especialmente lastimado por el conflicto son las esposas de los presos políticos. Separadas de sus maridos durante periodos a menudo indeterminados ${ }^{4}$, están obligadas a compaginar una onerosa defensa legal y penosas visitas a cárceles israelíes, con la responsabilidad de atender las necesidades de sus familias (EMHRN 2014, 32-38).

Ante la evidencia de las relaciones entre género y conflicto, conviene alejarse de lecturas estereotipadas según las cuales los hombres serían los únicos protagonistas de los conflictos, y las mujeres víctimas ajenas a las tensiones políticas, económicas, étnicas, confesionales o ideológicas subyacentes. Esta visión, que perpetúa la objetivación de las mujeres, reservando la condición de sujeto a los hombres, no suele responder a la realidad de ninguna guerra. Como reconoció la UNSCR 1325, las mujeres no son solamente víctimas de los conflictos armados, sino también agentes activos en su prevención y resolución.

Se ha constatado que los contextos bélicos pueden favorecer la incorporación de las mujeres a actividades tradicionalmente reservadas a los hombres, aunque es cierto que esta subversión de los roles de género tiene en general un carácter temporal. En el caso que nos ocupa, la pérdida de empleo masculino palestino en los sectores de la agricultura y la construcción en Israel a raíz de la Segunda Intifada, ha propiciado la participación económica de las mujeres para compensar la mengua de ingresos familiares. Sin embargo, como pudo comprobar el Banco Mundial, esta incorporación femenina se dio mayoritariamente en trabajos precarios y mal remunerados o en actividades económicas informales, y no parece haber provocado cambios sustanciales en las relaciones de género dentro de las familias (World Bank 2010).

Nicola Pratt y Sophie Richter-Devroe alertan de otro riesgo epistemológico que aflora cuando se abordan las intersecciones entre género y conflicto:

4. Como es el caso de las llamadas «detenciones administrativas». 
el de avalar, como ha ocurrido en relación con Iraq y Afganistán, narrativas aparentemente feministas que, al representar a las mujeres del Sur como víctimas que deben ser «liberadas» por las «democracias occidentales», acaban justificando intervenciones militares imperialistas y deslegitimando a las organizaciones feministas locales. De acuerdo con estas autoras,

si se pasan por alto las relaciones complejas entre guerra y género, los discursos sobre la necesidad de «salvar a las mujeres» del Sur Global pueden provocar un retroceso local contra el activismo femenino en situación de conflicto y post-conflicto, que puede ser asociado con las intervenciones extranjeras y las agendas militares extranjeras. $(2013,2)$

Entre todos los aspectos de los estudios sobre género y conflicto, el que más interés suele recabar es la violencia de género y, más concretamente, la violencia sexual. Ya en los años setenta, Susan Brownmiller (15) demostró que la violación es un proceso consciente de intimidación a través del cual todos los hombres mantienen a todas las mujeres en un estado de miedo. En situación de conflicto, la violación es un arma de guerra con efecto atemorizador y desmoralizador. La violencia sexual simboliza la derrota de los combatientes y es percibida como una humillación del grupo entero, porque es en las mujeres, y más concretamente en sus cuerpos sexuados postulados por el patriarcado, que se suelen depositar las identidades nacionales, étnicas o comunitarias. Las mujeres son quienes «encarnan» la nación: la representan simbólicamente y la reproducen dando vida a sus futuros hijos.

También se ha demostrado que tanto en contextos bélicos como en tiempos de paz, la violencia sexual presenta altos niveles de impunidad, debido a factores que van desde la falta de acceso a la justicia, la ausencia de atención especializada y el carácter patriarcal de las leyes y operadores jurídicos, hasta el sentimiento de vergüenza de las víctimas y su miedo a las represalias y al estigma social (Nuño). En las sociedades árabo-musulmanas, las mujeres que han sido violadas corren el riesgo de ser repudiadas por sus maridos o rechazadas por sus familias. Pueden incluso ser forzadas a casarse con sus agresores o con el primero que tenga la «bondad» de hacerlo con una mujer que no entrega su virginidad como dote matrimonial ${ }^{5}$. Por todo ello, las víctimas suelen mantener en secreto los abusos sexuales, tanto si los autores pertenecen al bando enemigo como si son miembros de su propia comunidad.

5. Conviene recordar al respecto que la mayoría de los marcos legales de los países de mayoría musulmana, incluyendo los dos códigos penales vigentes en Cisjordania y Gaza, prevén el indulto del autor de una violación en caso de contraer matrimonio con la víctima. 
En sus informes periódicos, la Comisión Internacional Independiente de Investigación sobre la República Árabe de Siria reconoce que la violencia sexual juega un papel predominante en el conflicto sirio y señala la dificultad de valorar la magnitud del fenómeno, porque «lo común es que no se presenten denuncias de violencia sexual o que tarden en presentarse» (CDDHH2013), máxime cuando los agresores forman parte de las fuerzas gubernamentales, como suele ocurrir (EMHRN 2013, 9). Según las estimaciones de Red Siria de Derechos Humanos, se podrían haber perpetrado 6000 violaciones sólo en Siria en el año 2013.

En su informe We just keep silent, ONU-Mujeres señala que para más de la mitad de las refugiadas sirias en los campos del Kurdistán iraquí, el miedo a ser violadas es uno de los principales factores que motivaron su huida de Siria, un dato ya evidenciado en 2012 entre la población siria refugiada en el Líbano (4). Por su parte, la Relatora especial sobre violencia sexual en conflicto, Zainab Bangura dio la voz de alarma ante la extrema gravedad de los casos de violencia sexual contra mujeres y niñas en el conflicto que asola Siria e Iraq, después de entrevistarse con las mujeres yezidies que habían sido raptadas por ISIS en el Kurdistán, violadas innumerables veces, casadas a la fuerza y vendidas como esclavas sexuales en un mercado de Siria. Real o simbólica, la violencia sexual es omnipresente en todos los conflictos armados, pero antes de analizar su uso en el conflicto israelo-palestino, es preciso abordar la relación entre el nacionalismo palestino y el cuerpo de las mujeres.

\section{El cuerpo de las mujeres y el nacionalismo palestino}

A diferencia de lo que se observa en otros países árabes donde los nacionalismos poscoloniales han perdido fuerza, el imaginario nacionalista sigue articulando la identidad colectiva palestina. Esta singularidad tiene una explicación muy sencilla: Palestina nunca obtuvo su independencia. La retirada del protectorado británico propició en efecto la asunción de una nueva potencia colonial, bastante más aguerrida que las anteriores, dado que los colonos sionistas arribaron con la intención de fundar, sobre la tierra palestina, el «Hogar Nacional» del pueblo judío. La población autóctona árabe, como bien desvelaron los nuevos historiadores israelíes, no tenía cabida en el proyecto sionista de estado judío en Palestina (Shlaim).

La guerra de 1948 culminó con la creación del estado israelí y la huida de setecientas mil personas refugiadas. Una década más tarde nacerían las primeras guerrillas y en 1964 se institucionalizaría el movimiento nacionalista. En este contexto de independencia postergada, la liberación nacional se convirtió en eje aglutinador de todas las fuerzas políticas palestinas, y la 
identidad nacional se impuso sobre cualquier otra, incluyendo la confesional, como factor de movilización popular ${ }^{6}$. Dado que como señaló Michèle Le Doeuff, a las mujeres se les suele asignar en todas las sociedades, un plus o sobrecarga de identidad adscriptiva (Amoros 230; Femenías 2007, 188), la retórica nacionalista palestina desplazó el peso de la mencionada identidad nacional sobre las mujeres.

Veamos cuáles han sido los referenciales y significados de esta sobre-asignación identitaria generizada. Al hilo de su estudio de la relación entre nacionalismo palestino y masculinidad, Joseph Massad puso de relieve la analogía que la retórica nacionalista estableció entre tierra y mujer palestina. Siguiendo la lógica de esta metáfora, demostró que los textos fundacionales del nacionalismo palestino describen la conquista sionista de Palestina como una «violación» y su futura independencia como el «nacimiento de Intifada» (Massad 473; Jacoby 9).

La analogía romántica entre los constructos mujer y tierra tiene claras implicaciones en términos de jerarquía sexual, dominación patriarcal y posesión masculina. En palabras de Tami Amanda Jacobi:

La identificación del nacionalismo con la masculinidad simbolizada por la defensa del ard y el ird (tierra y honor) del patriarca palestino, convierte la tierra en símbolo de la integridad sexual de las mujeres y hace depender la lucha palestina del apoyo práctico y moral que éstas le brinden al dar a luz a nuevas generaciones de luchadores (9).

Con el fin de salvar la Nación palestina, mujeres y tierra deben ser protegidas de la violación sionista y fecundadas por el nacionalismo palestino. Sobre este trasfondo semántico, la virginidad femenina adquiere una dimensión sacralizada. Es más, ante la frustración simbólica de la masculinidad palestina por la progresiva colonización de la tierra palestina, el cuerpo de las mujeres ha devenido en único territorio sobre el que ellos no han perdido soberanía. En definitiva, la ecuación nacionalista mujer-nación ha afianzado el control patriarcal sobre el cuerpo, la sexualidad y la vida de las mujeres.

Al convertir a la mujer palestina en territorio nacional imaginario, se ha favorecido inconscientemente que los cuerpos de las mujeres fueran

6. Así atestiguan las siglas de los partidos palestinos, desde Fatah, acrónimo en árabe de Movimiento de Liberación Nacional de Palestina, hasta los marxistas Frente Democrático de Liberación Nacional (FDLP) y Frente Popular de Liberación Nacional (FPLP). Hasta el propio Hamas, fundado en 1987, se diferenciaría del movimiento de los Hermanos Musulmanes, añadiendo al ideario islamista un fuerte componente nacionalista (Carta Fundacional del Hamas, art. 12). 
«weapon-izados» (o transformados en $\operatorname{armas}^{7}$ ) tanto por el nacionalismo palestino como por el colonialismo israelí (Shaloub-Kevorkian 2009, 113). Como señalan las propias mujeres entrevistadas por Nadera Shaloub-Kevorkian, la retórica nacionalista ha explotado el cuerpo de las mujeres en su lucha demográfica contra Israel, al enfatizar su «rol reproductivo politizado», especialmente durante los episodios de militarización de la resistencia como la Segunda Intifada (Kuttab y Johnson 31).

\section{El cuerpo de las mujeres palestinas y el colonizador israelí}

Conviene ahora explorar los modos en los que Israel utiliza el cuerpo sexuado y el género de las mujeres palestinas con el fin de doblegar el nacionalismo palestino. Aunque su prevalencia, difícil de estimar, dista mucho de alcanzar los niveles observados en la vecina Siria, la violencia sexual ocupa un lugar central en el conflicto israelo-palestino desde sus inicios. La «weaponización» de las mujeres palestinas se remonta, en efecto, al periodo previo a la creación del estado de Israel ${ }^{8}$, cuando los grupos terroristas sionistas Irgun y Stern (de los que formaron parte altos cargos israelíes) sembraron el terror entre la población árabe autóctona, con el propósito de limpiar étnicamente la Palestina histórica. Las violaciones masivas de mujeres y niñas ante sus familias y los destripamientos con cuchillos de mujeres embarazadas durante la masacre de Deir Yassin en abril 1948, quedaron grabados en la memoria colectiva, y siguen hoy en día proyectando una sombra intimidatoria.

En la actualidad, los cuerpos de las mujeres palestinas son «weaponizados» por el ocupante israelí de diversas formas. En los checkpoints de Cisjordania son habituales las burlas y vejaciones que atentan contra la dignidad e integridad de las mujeres palestinas, obligándolas por ejemplo a quitarse el hijab delante de soldados masculinos. El sentimiento de inseguridad causado por este tipo de acoso disuade a muchas mujeres y niñas de realizar desplazamientos, restringiendo su acceso a la salud, la educación y el empleo, así como su participación social y política (Muhiar Muñumer 207-208).

La violencia de carácter sexual y la amenaza de su uso son también utilizadas para coaccionar a las mujeres palestinas, bien como técnicas de

7. El término de «weaponization» de los cuerpos de las mujeres se refiere según ShaloubKevorkian, a las «distintas formas en las que las fuerzas patriarcales propias y del ocupante utilizan sus cuerpos en el conflicto». No se traduce por considerar que la palabra inglesa expresa mejor el significado de la palabra.

8. Mientras la narrativa israelí lo llama «independencia» de Israel, la población palestina se refiere a la creación de Israel como la «Naqba», término que significa el «Desastre» en árabe. 
interrogatorio contra detenidas, bien a través del fenómeno conocido como isqat siyassy. Esta práctica ampliamente utilizada por las autoridades militares israelíes contra la resistencia palestina, consiste en acosar sexualmente, formular amenazas de contenido sexual y explotar las percepciones patriarcales de la sexualidad y el honor, con el propósito de reclutar a mujeres palestinas como colaboradoras o informadoras (Shalhoub-Kevorkian y otras, 2015). Por supuesto, cuan mayor es el elenco de conductas femeninas cultural y socialmente sancionables, mayores son las posibilidades de forzar la colaboración de mujeres palestinas con el enemigo. A diferencia de otras, esta violación de los derechos humanos suele pasar inadvertida por las autoridades y organizaciones palestinas, debido a que en el ideario nacionalista, la denuncia de este tipo de abusos es percibida como una forma de complicidad con las fuerzas de ocupación por el «daño» que causa a la nación palestina (Shalhoub-Kevorkian, 2009).

Otra manifestación del fenómeno, esta vez en el plano simbólico-discursivo, es la incitación a la violencia contra las palestinas, incluyendo la violencia sexual, formulada por miembros de la oficialidad israelí. Recuerdan Shalhoub-Kevorkian, Ihmoud y Dahir-Nashif que durante la operación militar contra Gaza de julio-agosto 2014, representantes israelíes hicieron públicamente la apología de la violencia contra las mujeres palestinas, bien promocionando la violación como única forma de prevenir los ataques contra colonos israelíes ${ }^{9}$, bien reclamando su asesinato masivo con el fin de impedir que den a luz a «terroristas» palestinos ${ }^{10}$ (2015). Recuperando la analogía entre mujer y nación sustentada por la narrativa nacionalista palestina, estas incitaciones al odio no solamente reducen a las mujeres palestinas a cuerpos sexuados que pueden ser violados y eliminados: también simboliza la destrucción del pueblo palestino y la conquista de su tierra. Para Israel, la violencia sexual contra las mujeres palestinas, real o figurativa, es inseparable de la lógica sionista de eliminación del proyecto nacionalista palestino y de limpieza étnica del territorio otrora consignado en los mapas como «Palestina».

9. El profesor israelí Mordechai Kedar, del Centro Begin-Sadat de Estudios Estratégicos, declaró en la radio pública: «Lo único que puede disuadir a... quienes secuestraron a los niños [israelíes] y los mataron, la única manera de disuadirles es que sepan que si los capturan, su hermana o su madre serán violadas... Esta es la cultura de Oriente Medio.». Ver Shalhoub-Kevorkian, Sarah Ihmoud y Suhad Dahir-Nashif, 2015.

10. La diputada israelí del partido israelí Hogar Judío, Ayelet Shaked, pidió en julio 2014, en plena operación contra la franja de Gaza, que se mataran a las madres de los terroristas palestinos «porque si no, volverán a criar pequeñas serpientes». 


\section{La identidad genérica por contraste}

Se ha demostrado que a través de la analogía mujer-tierra, el nacionalismo palestino enfatizó características que alimentaron discursos normativos de subordinación femenina inscritos en la teoría de la complementariedad sexual. Paralelamente, el modelo de mujer palestina también se construyó por oposición al constructo de mujer israelí y, por extensión, de mujer occidental. Joseph Massad señala que

Es una tarea importante para los nacionalistas anticoloniales, no solamente definir los roles de género el uno en relación con el otro (femenino-masculino), sino definir ambos en relación con el proyecto nacionalista y, al hacerlo, disociar la identidad nacional de cualquier contaminación colonial (470).

En este mismo sentido, concluye Sharoni que los discursos nacionalistas palestinos e israelíes, que «implican asunciones explícitas e implícitas sobre masculinidad, feminidad y relaciones de género», se han edificado sobre la distinción entre el nosotros/as y el ellos/as (37).

Por un lado, los sionistas asentaron su proyecto colonial en torno a la narrativa bíblica de la tierra prometida, dándole la espalda a la identidad árabo-musulmana de Oriente Próximo, que describirá oportuna y deliberadamente como hostil y bárbara. Como es fácilmente observable, la sociedad israelí, con la salvedad de la comunidad ortodoxa, comparte patrones de consumo, comportamentales y vestimentarios con Europa y EEUU; y ello a pesar de la gran diversidad étnica de las comunidades judías que han emigrado a Israel. El proceso de aculturación se ha basado en el modelo cultural capitalista occidental, facilitando así la normalización de un estado colonial en una época poscolonial, y la benevolencia de Occidente respeto del sistema de Apartheid establecido por el estado israelí.

El nacionalismo palestino siguió, por otra parte, el mismo patrón que el resto de movimientos anticoloniales de la región, los cuales construyeron sus identidades nacionales reafirmando su arabidad para desmarcarse de unas potencias occidentales que los habían mantenido en posición subalterna. Con el retroceso más reciente de los nacionalismos panarabistas seculares, la identidad árabe se ha resignificado en torno al componente religioso, hasta configurar una especie de identidad árabo-musulmana que acaba invisibilizando a las minorías étnicas y comunidades cristianas. En el contexto actual de globalización neoliberal e invasiones militares imperialistas, sobre todo desde el 11-S, el rechazo reavivado a Occidente ha sido explotado por las fuerzas islamistas, que han convertido en prioridad colectiva salvaguardar la 
«autenticidad» islámica contra las influencias extranjeras. Un fenómeno que se puede interpretar como fortalecimiento de las identidades reactivas.

Partiendo de la crítica que hizo Edward Said al orientalismo, se mantiene desde posturas feministas contra-hegemónicas que, al dar centralidad a la emancipación de las mujeres indígenas, los colonos occidentales desarrollaron una narrativa que reduce la identidad árabe al control masculino sobre las mujeres. Como explica Huma Ahmed-Gosh,

Se puede historiar el «uso político» de los cuerpos de las mujeres desde la colonización. La fascinación de los colonizadores y de los ocupantes occidentales más recientes por la segregación de las mujeres del espacio público, ha sido alternadamente romantizada, exotizada y básicamente utilizada para definir la región como retrógrada, y ha conducido a guerras con la retórica de «liberar»a las mujeres (100).

Paralelamente, para las comunidades colonizadas, la resistencia al cambio en el ámbito de la familia y la "protección» de las mujeres contra la influencia occidental llegaron a simbolizar el mantenimiento de la autenticidad islámica, la dignidad colectiva y la continuidad social (Moguissi 36).

Esta equiparación entre emancipación femenina y cultura occidental ha tenido dramáticas consecuencias para muchas feministas árabes, que al defender la igualdad de género, han sido asociadas con el opresor y acusadas de falta de autenticidad cultural. Como señala Denyz Kandiyoti, «Cualquier intento de cambiar la posición de las mujeres podía (...) ser relacionado con fines imperialistas o neo-imperialistas, y las colaboradoras locales de tal proyecto ser teñidas de falta de autenticidad, cuando no de traición» (7). Una argucia que las estructuras patriarcales locales han sabido explotar para deslegitimar las reivindicaciones de las mujeres, especialmente cuando provienen de lo que se ha venido llamando el feminismo «secular».

Si bien es cierto que la construcción identitaria generizada en reacción a y por contraste con el colonizador ha contribuido al afianzamiento de la subordinación de las mujeres, sería erróneo considerar que el origen de las prácticas sexistas y androcéntricas en las sociedades árabo-musulmanas, reside en la mera oposición al imperialismo occidental. Muchas de las normas patriarcales actuales guardan relación con factores previos o ajenos al colonialismo, como: las relaciones de género propias de las estructuras de clanes; la inexistencia de una revolución industrial, clave en Occidente, que transformara el rol de las mujeres; el estatuto de súbditos y no de ciudadanos que los dirigentes de los nuevos estados nacidos de la descolonización intentaron imponer a sus poblaciones; y la importancia de los mandatos religiosos en la vida social y política (Thill). 
En el caso de Palestina, el colonialismo israelí ha influido considerablemente en la identidad nacional del pueblo ocupado, y en el código prescriptivo asignado a las guardianas de esta identidad. En un contexto de creciente interculturalidad favorecida por el contacto permanente con el ocupante, se ha impuesto como necesidad vital resistir el sociocidio-espaciocidio-genocidio por la vía identitaria. Para las mujeres palestinas, diferenciarse de las mujeres israelíes no sólo equivale a reafirmar la identidad colectiva, sino a establecer fronteras culturales como estrategia de supervivencia como pueblo. En los dos próximos apartados, se analizará cómo las opciones políticas mayoritarias palestinas, a saber el nacionalismo de Fatah y el islamismo de Hamas, abordan los derechos de las mujeres palestinas, y qué diferencias y similitudes presentan sus proyectos generizados de sociedad.

\section{La autoridad nacional palestina y la igualdad legal}

Cuando afirmó que «los derechos de las mujeres y los derechos humanos se promueven y protegen mejor en un entorno de pensamiento e instituciones seculares», la autora iraní Valentine Moghadam formuló una opinión compartida por muchas activistas y académicas (1162). Según esta premisa, Fatah, el partido nacionalista que lidera la Autoridad Palestina (AP) y la secular Organización de Liberación de Palestina (OLP), ambos creados en 1964, deberían haber optado por la igualdad de género y los derechos de las mujeres. Pero los textos fundacionales y el marco legislativo vigente arrojan una realidad llena de matices o contradicciones.

Por un lado, la Declaración de Independencia de 1988 proclamada por Yasser Arafat en el año uno de la Primera Intifada, y la Ley Básica refrendada en 2002 y enmendada en 2003 y 2005, reconocen el principio de igualdad sin discriminación por razón de sexo. De ello se podría deducir que Palestina cuenta con una base legal suficiente para desarrollar leyes, políticas e instituciones no discriminatorias ${ }^{11}$. Y así sería si no fuera porque estos marcos cuasiconstitucionales adoptan posiciones divergentes sobre la relación del futuro estado palestino con el Islam, religión mayoritaria que siempre ha convivido de forma pacífica con el cristianismo. La única referencia a la religión en toda la Declaración de Independencia, que redactó el poeta Mahmoud Darwish, asienta al gobierno democrático palestino en «el respeto por la multisecular

11. El caso de las acciones positivas requeriría una mención sobre igualdad real, como Hallie Ludsin recomienda introducir en la futura Constitución palestina. Ver Ludsin, 2011. 
herencia espiritual y civilizacional palestina de tolerancia y coexistencia religiosa» (Consejo Nacional Palestino 1988).

Diez años más tarde, la Ley Básica se distanció del secularismo inicial al establecer que los «principios de la sharía constituyen una fuente principal de legislación» (art.4) y que las cuestiones de estatuto personal serán competencia de tribunales religiosos o de la sharía (art 92). Aunque la formulación del rol de la ley islámica («una fuente principal») permite situar la Ley Básica entre las más progresistas de la región ${ }^{12}$ (hecho que se explica en parte por la importancia de la población cristiana en Palestina), organizaciones de mujeres y de derechos humanos palestinas han señalado que, dado que la sharía ${ }^{13}$ avala el trato discriminatorio hacia las mujeres en aspectos civiles, penales y procesales, los artículos 4 y 92 de la Ley Básica entran en contradicción con la igualdad de hombres y mujeres consagrada en el artículo 9 (Ludsin).

$\mathrm{Al}$ amparo de esta ambigüedad interna de la Ley Básica, se han mantenido vigentes Códigos Penales y del Estatuto Personal heredados del protectorado británico, de Jordania y Egipto, inspirados en la sharía, que vulneran el principio de igualdad de género ${ }^{14}$. Las disposiciones discriminatorias más relevantes son, en el ámbito civil: las relativas al matrimonio, al divorcio y la custodia de los hijos/as. En el ámbito penal: la pena aplicable en casos de llamado «crimen de honor», la legalidad de la violación en el matrimonio y la posibilidad de escapar a la pena casándose con la víctima. Y en el ámbito procesal: la devaluación del testimonio de las mujeres hasta el punto que su intervención en los procesos judiciales se considera como «medio testigo».

Cierto es que la Autoridad Palestina, bajo la presión del movimiento feminista local y de la comunidad internacional, ha dado algunos pasos en favor de la igualdad de género en la legislación palestina. A saber la adhesión a la CEDAW en el año 2009 y la promulgación de un Decreto Presidencial el 15

12. Sobre la diversidad de la sharía en los diferentes sistemas legales, se recomienda la lectura de Lombardi (2013).

13. Con sharía, nos referimos a la sharía legal o clásica definida por Pedro Buendía Pérez como «shari’a clásica, de carácter eminentemente técnico y premoderno, que sería el conjunto de la jurisprudencia inspirada en el Corán y la sunna, codificada y desarrollada por las diversas escuelas y jurisconsultas aproximadamente hasta el siglo X, y posteriormente aplicadas de manera desigual en algunas parcelas del derecho, especialmente en el derecho de la familia y en menor grado en el ámbito penal» (144). Como señala Thierry Desrues, «aunque haya unanimidad en los principios, la interpretación de la noción de la Sharía y las condiciones concretas de su aplicación dan lugar a notables diferencias según los movimientos y los países, puesto que la casuística que entraña su aplicación se acomoda o enfrenta en distinto grado a las culturas locales» (14).

14. Sobre este último, se recomienda la lectura del estudio de WCLAC y DCAF (2011). 
de mayo 2011 suspendiendo el artículo 340 del Código Penal de 1960 vigente en Cisjordania y el artículo 18 del Código Penal de 1936 vigente en Gaza, que disponían que el llamado «crimen de honor» constituye una circunstancia atenuante. Pero estas medidas tuvieron un efecto más simbólico que real. Por un lado, la CEDAW no ha sido vinculante hasta su ratificación en 2014 ni ha acarreado la esperada revisión de leyes. $\mathrm{Y}$ en cuanto al mencionado decreto adoptado en respuesta al asesinato de la joven Ayah Baradiyya ${ }^{15}$, no derogó el artículo 340 del Código Penal de 1960, sólo lo suspendió, y mantuvo la vigencia de otros artículos de similar contenido (WCLAC y DCAF 2012).

En lo relativo a la participación política de las mujeres, el balance también presenta claroscuros. Como suele ocurrir universalmente, el movimiento nacionalista no ha cedido a las mujeres palestinas el espacio que les correspondía en el gobierno, a pesar de su valiosísima contribución a la lucha de liberación nacional y del papel estratégico que desempeñaron durante la Primera Intifada (Kuttab y Johnson). Las expectativas del movimiento feminista de participar en la construcción del estado palestino se vieron ampliamente truncadas (Abdo). Así, en el gobierno de la primera Autoridad Nacional Palestina creada en mayo 1994, sólo participó una mujer, Intisar Al-Wazir, como Ministra de Asuntos Sociales.

Con el paso de los años, algunas mujeres se han ido haciendo hueco en las instituciones gubernamentales y el número de ministras ha experimentado un leve incremento. En la actualidad, en un gabinete compuesto por quince ministros, sólo hay tres mujeres y ocupan la cartera sexo-específica de Asuntos de las Mujeres, el Ministerio de Turismo y Antigüedades (poco relevante en un contexto de ocupación militar), y el Ministerio de Educación. Esta incorporación de las mujeres en el gobierno palestino ha encontrado fuertes resistencias patriarcales. Conviene recordar al respecto la polémica surgida en torno al nombramiento de la Ministra encargada de la política educativa, la Dra en Educación Científica por la Universidad de Carolina del Norte y ex-decana de la Universidad de Birzeit, Khawla Shakhshir, cuando un miembro del Comité Central de Fatah supuestamente descartado para el puesto, declaró públicamente que había sido nombrada por sus vínculos familiares con el Primer Ministro del actual gobierno de unidad nacional, y no por su recorrido académico y su experiencia profesional (Al-Sahna). Un fenómeno

15. Esta joven de Hebrón fue asesinada en 2011 por su tío paterno, supuestamente como castigo por verse con un compañero de la facultad. El hallazgo de su cuerpo en un pozo tres meses después de su desaparición, obtuvo una gran repercusión en la sociedad palestina y en medios internacionales, lo que obligó a la Autoridad Palestina a reaccionar. 
desgraciadamente observable en mayor o menor medida en todos los contextos culturales.

La co-fundadora del Instituto de Estudios de la Mujer de la Universidad de Birzeit, Islah Jad, atribuye la ambigüedad histórica del posicionamiento de la OLP y de la AP en cuestiones de igualdad de género, a una tensión entre el secularismo declarativo y una especie de compromiso implícito con la interpretación popular del Islam. Citando a Kandawati, recuerda que

Aunque muchos nacionalismos de naturaleza secular fueron influenciados por ideas de la Ilustración, también adoptaron de manera subconsciente la idea de que cualquier cambio en la posición de las mujeres sólo era aceptable si servía el interés nacionalista (Jad 2010).

Dado que respaldaban la retórica nacionalista de la mujer palestina depositaria de los valores tradicionales de vida rural, maternidad, humildad, pureza y autenticidad, los preceptos islámicos sobre matrimonio, divorcio, sexualidad o herencia, fueron de gran utilidad para el liderazgo secular. Esto explicaría por qué los intentos del movimiento feminista palestino de igualar los derechos de mujeres y hombres en la legislación, fracasaron estrepitosamente (Giacaman y otras; Jad 2010). Heterodesignadas ${ }^{16}$ como guardianas de la identidad nacional, las mujeres palestinas no obtuvieron la igualdad formal proclamada por la Declaración de Independencia.

También constituyeron obstáculos a la eliminación de disposiciones legales discriminatorias, los siguientes factores: la ocupación israelí que priva al pueblo palestino de su derecho a la autodeterminación y posterga la posibilidad de dotarse de una constitución y un marco legal coherente y moderno que sustituya un sistema legal vetusto, complejo y geográficamente heterogéneo; la represión israelí que altera gravemente el funcionamiento democrático de las instituciones palestinas al mantener en detención a más del diez por ciento del Consejo Legislativo Palestino (CLP) ${ }^{17}$; y la falta de prioridad atribuida la igualdad de género por la AP, el CLP y el Poder Judicial, la cual debe ser interpretada no sólo como una manifestación de las habituales resistencias patriarcales a la transformación de las relaciones de género, sino también en términos de estrategias políticas y electorales de los partidos palestinos. Otro elemento de peso, como se estudiará en el siguiente apartado, es la creciente acogida del islamismo político en Palestina.

16. En el sentido apuntado por Amelia Valcárcel y Celia Amorós, de identidades asignadas por el patriarcado, y no por sí mismas.

17. Catorce de ciento treinta y dos miembros del CLP, la mayoría de ellos bajo la figura de la detención administrativa, incluyendo a la feminista del partido FPLP Khalida Jarrar. Ver. Addameer, Detained Palestinian Legislative Council Members, Abril 2015. 
En resumen, el mantenimiento de leyes discriminatorias hacia las mujeres palestinas en ningún caso puede atribuirse a la dificultad técnica de esta reforma, puesto que tal dificultad no existe. Como explicó Shawan Jabbarin de la organización Al-Haq, un comité de expertos y expertas en derechos humanos, organizaciones de mujeres y representantes ministeriales redactó un borrador de Código Penal moderno y lo entregó en 2011 a la AP, pero «el Presidente no lo firmó y lo tiene guardado en un cajón» (Melhem).

\section{Hamas, islamización y género: otra capa al constructo «mujer palestina»}

Existen muchos motivos y son complejas las dinámicas que han hecho posible que el islamismo ${ }^{18}$ obtuviera la popularidad que tiene hoy en día en el mundo árabo-musulman, como atestiguan los resultados de las primeras elecciones libres y democráticas celebradas en Egipto y Túnez después de los levantamientos populares de 2011. En Palestina, las principales razones que explican la victoria del Hamas en las elecciones de 2006, apenas dos décadas después de su fundación ${ }^{19}$, son: la desesperación y la frustración de la población por las durísimas condiciones de vida bajo ocupación israelí; la drástica pérdida de legitimidad sufrida por la AP a lo largo de unas negociaciones percibidas como improductivas e incluso contraproducentes; y la apropiación islamista de la lucha nacionalista por los derechos nacionales palestinos.

La islamización de la política y de la sociedad palestina, sobre todo en la Franja de Gaza donde Hamas gobierna de facto desde 2006, ha echado una capa suplementaria de identidad sobre las mujeres, dándole una apariencia nueva al ideal de mujer palestina e imponiendo estrictas normas de conducta

18. Utilizada por el sudanés Hassan Al-Turabi para designar a «los políticos musulmanes para quienes el Islam es la solución, el Islam es la religión y el Islam es la Constitución y la Ley» (Mozaffari 20), la palabra islamismo se refiere aquí a la ideología políticoreligiosa heterogénea, integrada por varias corrientes del Islam (sunní, shií y wahhabí), y nacida con los Hermanos Musulmanes en Egipto en 1928. Sus máximos teóricos fueron el egipcio Sayyid Qotb asesinado en 1966, el paquistaní Mawdudi y el iraní Jomeini (Kepel 27). Una de sus principales características es la voluntad de restaurar el califato musulmán desmembrado por los colonos occidentales, estableciendo un estado islámico (que no debe confundirse con el grupo terrorista así autoproclamado o ISIS) donde el gobierno sea de Allah y la ley sea islámica (sharía), sin renunciar a la lucha armada (yihad) cuando sea necesario a sus fines. Ver: Kepel; Mozaffari; Desrues).

19. Hamas es el partido islamista mayoritario en Palestina. Procedente de los Hermanos Musulmanes egipcios, Hamas es un partido de ideología islamista y nacionalista, que llama a la yihad contra Israel para liberar a Palestina, donde están los Lugares Sagrados de Al-Aqsa. Ganó las elecciones legislativas de 2006, y tras una breve guerra civil en la Franja de Gaza, gobierna este exiguo y sobrepoblado territorio. Su brazo armado es la Yihad islámica. En Gaza, ha logrado frenar el avance de grupos salafistas más radicales, incluyendo el ISIS o Daesh. 
a las palestinas reales. La famosa abaya tradicional palestina (larga túnica blanca o negra adornada con bordados de colores geométricos) fue sustituida por otra lisa y negra, que debe acompañarse del incondicional hiyab (velo que cubre el cabello) o del niqab (velo negro que sólo dejar entrever los ojos). Este código vestimentario depurado ha pasado a simbolizar la «renovada» identidad nacional palestina asociada a la religión islámica. A la vez, se ha convertido en señal de respeto a las normas de conducta femenina propugnadas por las autoridades islámicas.

Reem Hammami ya denunció en 1990 las prácticas coercitivas utilizadas por Hamas para imponer el hiyab en Gaza, como reacción a la penetración de costumbres importadas de Israel por los palestinos residentes en la Franja que trabajaban en Israel. Lamentaba en su artículo, la tardanza del entonces Liderazgo Unificado Palestino en condenar las agresiones acaecidas contra mujeres que no llevaban el velo, concluyendo que «ni la promulgación del hiyab por los islamistas ni los elementos conservadores de la sociedad palestina contrarios a la independencia política de las mujeres, fueron adecuadamente respondidos por el liderazgo nacional palestino» (28). Cabe señalar que el proceso de islamización de la sociedad palestina fue indiscutiblemente exitoso. Hoy en día, en Gaza, el hiyab es de uso obligatorio en las universidades, escuelas y tribunales, y raras son las mujeres que no lo llevan. Para muchas palestinas, se ha convertido en una señal de identidad frente al ocupante israelí.

Si bien inicialmente, la ideología de género de Hamas consagraba la figura de la mujer dependiente del marido y confinada en el hogar, su discurso sobre participación de las mujeres en el trabajo, la política y la lucha armada ha evolucionado, dando muestra del gran pragmatismo de sus líderes. Con el propósito de ampliar su base social entre las mujeres, ganar prestigio internacional y competir con el movimiento feminista secular, el partido islamista lanzó una estrategia específica sobre mujeres que incluía la financiación de servicios a través de sociedades caritativas, el reclutamiento de profesionales formadas, la creación de una Sección de Acción Femenina («Women’s Action Department») y la celebración de conferencias sobre cuestiones relativas a la situación de las mujeres. En consecuencia, al tiempo que utilizaba la sharía para desacreditar la noción de soberanía popular como fuente de legislación y desautorizar a las organizaciones feministas seculares, Hamas se vio obligado a suavizar sus planteamientos originales, incorporando en su discurso algunas demandas formuladas por las propias militantes islamistas, aunque siempre dentro del marco de la sharía (Jad, 2010). 


\section{Feminismo e islamismo: haciendo de necesidad virtud}

Desde la posición de autoridad que le confiere su naturaleza religiosa, el islamismo ha cuestionado el principio de universalidad de los derechos humanos individuales, alegando que encubre fines imperialistas de Occidente (Jad 2010 , 9). Por su vocación totalizadora, ha sido llamado «fundamentalismo islámico» por académicas feministas como Haydeh Moguissi, Amanda Jacoby o Gita Saghal. Otro motivo de desencuentro entre el islamismo y el feminismo ilustrado, sea de izquierdas, radical o liberal, es la jerarquía sexual consagrada en el Corán, difícilmente compatible con el concepto de igualdad de género (Ahmed Gosh 103).

Es un ejercicio epistemológico necesario para cualquier persona que quiere acercarse a las mujeres en contextos de islamización o re-islamización, ser precavida con el uso de la categoría de «feminismo islámico» que se ha venido utilizando de forma a veces equívoca para referirse a corrientes del movimiento de mujeres a veces muy distintas, caracterizadas por diferentes ideologías, teorías, estrategias y métodos. Conviene no utilizar el vocablo para referirse a las feministas árabes seculares que, siendo de confesión musulmana o no, enmarcan sus demandas, haciendo de necesidad virtud, en los contextos culturales, políticos y legales vigentes, bien por razones estratégicas, bien porque el islamismo hegemónico no les permite cuestionar abiertamente la sharía.

Entre las feministas islámicas propiamente dicho, han ganado especial visibilidad las eruditas que reinterpretan el Corán para demostrar su compatibilidad con los derechos de las mujeres y rebatir preceptos discriminatorios erróneamente atribuidos, según ellas, a los textos sagrados. Moguissi señala que un número creciente de académicas seculares han abrazado el feminismo islámico, por considerar que es la única forma de emancipación viable para las mujeres musulmanas o incluso para evitar ser descalificadas por «elitistas», «modernistas» y por estar «orientadas hacia occidente» (134).

También se ha utilizado la categoría de feminismo islámico para referirse a las activistas musulmanas que demandan más derechos para las mujeres, a menudo sin cuestionar la jerarquía sexual ni los roles de género en el ámbito de la familia. Finalmente, están las islamistas ${ }^{20}$, independientes o adscritas a un partido islamista, que defienden en el marco de su actividad sociopolítica,

20. El término «islamista» remite a la ideología política islamista, no es el equivalente de «musulmana» $\mathrm{O}$ «islámica». 
los intereses de las mujeres, especialmente en la esfera pública, al igual que defienden los principios islamistas y la aplicación de la sharía ${ }^{21}$.

Sobre la cuestión de la compatibilidad entre Islam y feminismo, las académicas están divididas. Mientras existen autoras que defienden que el feminismo islámico es el único feminismo fiel a las tradiciones autóctonas, otras consideran que es un oxímoron (Mojab 25). Mir-Hosseini y Jad recomiendan adoptar una definición de «feminismo» lo más amplia posible para poder identificar como tales a las mujeres islamistas que son conscientes de la discriminación de las mujeres y desempeñan actividades destinadas a mejorar sus vidas, distinguiéndolas así de las mujeres islamistas que no tienen esta preocupación (Mir-Hosseini 6; Jad 2010, 7).

Otras autoras emiten reservas sobre la categoría de feminismo islámico porque consideran que el Islam no es el marco adecuado para defender los objetivos del feminismo al no ser compatible la sharía con el principio de igualdad entre mujeres y hombres (Moguissi 141; Ahmed Gosh 103). Bastante razonable parece el criterio de Margot Badrán según el cual no se debería utilizar el término «feminista» para referirse a las mujeres islamistas que no se identifican con él, aun cuando defienden algunos derechos de las mujeres (Badrán 230; Jad 2010, 2). La clave probablemente consiste en preguntarse si la ideología, la teoría o la práctica en cuestión defiende el principio de igualdad entre hombres y mujeres o si, por el contrario, avala la jerarquía sexual.

Teniendo en cuenta el entusiasmo que activistas y académicas feministas pertenecientes a la corriente posmoderna y poscolonial profesan por el «feminismo islámico», es importante recordar que cualquier intento de teorización se debe asentar en el estudio crítico y diacrónico de los movimientos feministas locales. Al respaldar la idea según la cual el feminismo islámico sería el único marco indígena y viable de liberación de las mujeres árabes, se suele ignorar la realidad de los movimientos feministas nacionales autóctonos, mayormente seculares. Asimismo, el apoyo acrítico a una corriente feminista esencialmente hermenéutica, cuyas conclusiones sobre el carácter progresista del Islam guardan a menudo pocos vínculos con la realidad que viven las mujeres musulmanas, puede hacer correr el riesgo de sobredimensionar su capacidad emancipadora (Ahmed Gosh).

21. Karam distingue, por su lado, entre tres tipos de feministas: las feministas seculares, las feministas musulmanes que utilizan las fuentes islámicas como el Corán y la Sunna para demostrar que el discurso de la igualdad es válido dentro del Islam, y las feministas islámicas que son conscientes de la opresión e intentan rectificar la situación, pero no se llaman feministas (Karam 1998,10; Jad 2010, 7). 
A su vez, se puede acabar reforzando la estrategia de (re)-islamización de la sociedad mediante re-significación del constructo de mujer árabe según unas pautas cuya autenticidad o indigenismo no deja de ser discutible (Hammami). Como alerta Ahmed Gosh,

Los feminismos islámicos pueden acabar siendo utilizados por estados confesionales extremistas para mostrar al mundo occidental que el Islam predica la igualdad de género, mientras para las mujeres de esos estados, la realidad sigue siendo de opresión, irónicamente en nombre del Islam (106).

Al igual que el neoliberalismo occidental, el islamismo busca en efecto universalizar su marco normativo e ideológico y homogeneizar prácticas e identidades culturales, invisibilizando la diversidad étnica, religiosa, cultural e ideológica de las sociedades a las que quiere adoctrinar.

En Oriente Próximo, donde coexisten muchas comunidades religiosas y étnicas, el movimiento feminista esencialmente secular, ha establecido alianzas estratégicas con mujeres islamistas con el fin de avanzar en la conquista de sus derechos, dejando fuera del ámbito de estas iniciativas su objetivo a largo plazo de despatriarcalización de la política, la cultura y la economía. Esta nueva vía, que Ahmed Gosh nombra feminismo híbrido, es quizás la que mejor contribuye al objetivo de desencializar las diferencias culturales, basándose en la constatación de que «tanto empírica como normativamente, la justicia intercultural entre grupos humanos debería defenderse en nombre de la justicia y la libertad y no de una elusiva preservación de las culturas» (Benhabib 26; Lagarde 288).

\section{El movimiento de mujeres Palestinas: entre resistencias y negociaciones}

Se ha reservado deliberadamente esta cuestión para el final para que pueda valorarse en toda su dimensión la genialidad de este movimiento que ha tenido que combinar sus estrategias de reivindicación de derechos de las mujeres con la prioridad nacional de liberación de Palestina. Desde las primeras asociaciones de mujeres creadas bajo protectorado británico hasta las actuales organizaciones feministas, el activismo femenino siempre se ha enmarcado en el movimiento de liberación nacional. Tal es el énfasis dado a la contribución del movimiento de mujeres a la resistencia palestina, que en la literatura existente sobre mujeres palestinas, es más frecuente ver resaltado su papel en la Primera Intifada o sus altísimos niveles de agencia para hacer frente a la ocupación israelí, las agresiones militares y la crisis humanitaria, que la labor 
del movimiento de mujeres en avanzar una agenda feminista, incluyendo su lucha por prevenir y criminalizar la violencia de género.

Según Jacoby, no fue hasta la década de los setenta cuando el asociacionismo de mujeres adquirió las características de un movimiento feminista, convirtiéndose simultáneamente en un movimiento de base amplia y diversificada, compuesto por mujeres cristianas y musulmanas, burguesas y populares, rurales y urbanas. Su génesis nacionalista ha determinado su evolución, siendo una de las primeras manifestaciones de su dependencia de las fuerzas nacionalistas palestinas, la escisión en 1980 de la unitaria Unión Palestina de Comités de Trabajo de Mujeres (PUWCC) que se había creado dos años antes, en cuatro organizaciones adscritas a los principales partidos de la OLP: Fatah y los marxistas-leninistas Frente Popular de Liberación de Palestina (FPLP), Frente Democrático de Liberación de Palestina (FDLP) y Partido del Pueblo Palestino (PPP) (Jacoby).

A veces el movimiento feminista palestino tuvo que pagar un alto precio por transitar en la órbita de las grandes fuerzas nacionalistas seculares. La división del nacionalismo palestino en torno al Proceso de paz de Oslo ${ }^{22}$ fue en efecto el principal motivo por el cual se perdió la oportunidad de exigir colectivamente la implementación de la Carta de las Mujeres. Adoptada en 1994 por todas las organizaciones de mujeres palestinas, incluyendo la Unión General de Mujeres Palestinas (PWGU), esta agenda común desarrollaba una lista de derechos nacionales, políticos, sociales y económicos de las mujeres, sobre la base del principio de igualdad consagrado en la Declaración de Independencia de 1988 (Kuttab y Johnson 28).

Sobre el efecto de las negociaciones de paz en el movimiento de mujeres palestinas, las académicas suelen discrepar. Kuttab y Johnson consideran que, entre todos los movimientos sociales, el feminista ha sido uno de los más exitosos en superar el efecto desmovilizador del proceso de Oslo, atribuyendo esta excepción a que, salvo casos aislados como Hanan Ashrawi, las lideresas palestinas fueron excluidas de las primeras estructuras de gobierno. Menos

22. El proceso de Oslo es el proceso de negociaciones de paz iniciado en 1993 después de conversaciones secretas celebradas en la capital noruega entre el gobierno de Israel y la OLP. A diferencia de la vía multilateral seguida en la Conferencia de Madrid (1991), Oslo inauguró el modelo de negociaciones bilaterales de paz, en las que ocupante y ocupado deben alcanzar de forma gradual la liberación de los territorios palestinos, siguiendo el modelo de paz por territorios. Oslo provocó una cisión en el movimiento nacionalista palestino: por un lado, el bando pro-Oslo integrado por los partidos Fatah, PPP y FIDA (escindido del FDLP), y por otro lado la Alianza de las Fuerzas Palestinas, compuesta de FPLP, FDLP y Hamas que se negaron a firmar la Declaración de Principios de 1993. 
optimista, Simona Sharoni opina que la división del nacionalismo palestino respecto del proceso de paz de Oslo debilitó al movimiento de mujeres organizado, especialmente a las organizaciones vinculadas al FPLP y el FDLP, que son las que defendían posiciones más progresistas sobre mujeres y género (119).

Otro factor de debilitamiento señalado por la autora es el auge de Hamas, muy inclinado, como se ha visto, a socavar la base social del movimiento secular de mujeres. Conviene asimismo no despreciar el impacto en el movimiento feminista palestino, de la pérdida de legitimidad de la secular AP, en un contexto de desencanto popular por la vía seguida en las negociaciones y por las crecientes denuncias de corrupción (Álvarez-Ossorio). Finalmente, apuntan Kuttab y Johnson que el activismo de mujeres habría experimentado un proceso de despolitización a raíz de la financiación internacional de proyectos de género diseñados para un contexto de construcción de un estado -reiteradamente postergado-, en vez de enmarcarse en la lucha sostenida por la independencia de Palestina (25).

El movimiento de mujeres palestino es un movimiento de resistencias. Resiste contra el ocupante israelí con el sumud ${ }^{23}$ que lo caracteriza, y resiste contra las fuerzas patriarcales locales. Pero también es un movimiento de negociaciones. Negocia para conseguir mayores cuotas de igualdad, y también ha pisado las arenas movedizas de las negociaciones bilaterales con Israel.

\section{A modo de conclusión: lecciones aprendidas sobre mujeres y paz en Palestina}

La agenda de mujeres y paz en Palestina se remonta a la década previa a la aprobación de la Resolución 1325. Iniciado en la Primera Intifada, el diálogo por la paz entre mujeres israelíes y palestinas, empezó a florecer a raíz de las negociaciones de paz de Oslo. Apoyadas de forma entusiasta y acrítica por muchas feministas occidentales, las iniciativas conjuntas atrajeron el interés de los medios y de la academia. También recibieron financiación de agencias de cooperación, lo que permitió que organizaciones no gubernamentales como el Jerusalem Link y órganos más institucionales como la Comisión Internacional de Mujeres ${ }^{24}$ celebraran numerosos encuentros de mujeres,

23. El sumud palestino, un concepto que se ha traducido como perseverancia, y que es comúnmente asociado a las luchas diarias de las mujeres palestinas por mantener la vida de sus familias y comunidades, a pesar de y en respuesta a las prácticas israelíes orientadas a la evicción del pueblo palestino de su tierra (Richter-Devroe, 2011: 33).

24. El Jerusalem Link se fundó en 1994 como nexo entre la israelí Bat Shalom y la palestina Jerusalem Centre for Women. Integrada por personalidades sociopolíticas israelíes, 
conferencias internacionales, reuniones de incidencia y misiones al extranjero (Sharoni 121).

Pero a pesar del apoyo internacional, las iniciativas de diálogo entre mujeres palestinas e israelíes (en las que las organizaciones feministas palestinas opuestas al proceso de Oslo siempre se negaron a participar) fueron relativamente efímeras. Entre los factores contextuales que contribuyeron a su fracaso, padecieron una pérdida de credibilidad vinculada al estancamiento de las negociaciones oficiales de paz. En palabras de Richter-Devroe, «las mujeres eran invitadas a participar y contribuir en una negociaciones de «paz» que no desafiaban, sino preservaban, e incluso daban legitimidad al mantenimiento del control israelí sobre Palestina» (4). La creciente deserción de las mujeres palestinas en encuentros cada vez más polarizados y la cascada de dimisiones individuales en la Comisión Internacional de Mujeres (ICW), no siempre fueron comprendidas por las feministas israelíes e internacionales, que sacaron apresuradas conclusiones sobre una supuesta falta de voluntad de dialogar por parte de las representantes palestinas.

Al margen de las dificultades derivadas del colapso de las negociaciones oficiales, el principal error de estas iniciativas fue que, en su diseño, no se prestó la suficiente atención al desequilibrio estructural de poder y privilegios entre israelíes y palestinas, ni a las diferencias entre sus expectativas y agendas políticas (Sharoni). Mientras las mujeres israelíes, que no sufrían las consecuencias de una ocupación militar extranjera, buscaban las experiencias compartidas como mujeres y enfatizaban los conceptos de tolerancia y aceptación según el modelo de paz con cuidado, las palestinas, desde su posición de subalternas, adherían al modelo de paz con justicia, centrándose en las exigencias de liberación nacional, los derechos políticos del pueblo palestino y el derecho de retorno de las personas refugiadas.

En estos encuentros, el género era presentado como punto de conexión pero descontextualizado o despolitizado (Richter-Devroe ${ }^{25}$ ). Para utilizar un concepto desarrollado por la teoría feminista, los parámetros del diálogo ignoraron la intersección entre género y ocupación, conduciendo irremediablemente a un cortocircuito comunicativo. Debido a que no reconocieron la asimetría contextual del diálogo entre ocupante y ocupada, ni tomaron las medidas adecuadas para remediarla (que es también el error conceptual de los sucesivos procesos de paz en Palestina), estas iniciativas conjuntas de mujeres

palestinas e internacionales, la Comisión fue creada en 2005 para monitorear la implementación de la 1325.

25. http://www.e-ir.info/2012/12/28/unscr-1325-in-palestine-strengthening-or-disciplining-womens-peace-activism/ 
palestinas e israelíes presentaban pocas probabilidades de sobrevivir a los vaivenes de las relaciones bilaterales entre Israel y Palestina.

Como señala María Luisa Femenías, «dialogar situadamente implica hacerlo con conciencia de la no homogeneidad de los espacios y de las diferencias en los puntos de inicio conversacionales» $(2013,273)$. La importancia de situar el diálogo se ve reflejada en el enfoque adoptado por la Coalición de Mujeres por la Paz (CWP en sus siglas inglesas). Esta plataforma asamblearia israelí integrada por nueve organizaciones feministas ${ }^{26} y$ mujeres independientes, se inscribe en lo que Sharoni define como politicas de solidaridad. Consciente de que la asimetría entre ambos movimientos feministas radica en la ocupación militar de Palestina, la Coalición integró entre sus objetivos la lucha contra esta situación colonial. Con este propósito, adoptó la estrategia de resistencia pacífica anti-Apartheid propuesta por el movimiento de mujeres palestinas, siendo una de las primeras organizaciones israelíes en adherirse a la campaña de Boicot, Desinversiones y Sanciones contra Israel ${ }^{27}$ (Sharoni 123). Numerosas organizaciones feministas, pacifistas y antimilitaristas de Europa, Estados Unidos y otras regiones del mundo seguirían el mismo camino ${ }^{28}$.

En relaciones radicalmente asimétricas, el compromiso solidario por acabar con la situación de injusticia, utilizando a tal efecto las estrategias que la parte oprimida nos propone, es la única forma de abrir canales alternativos para acceder a una otra real, o mejor dicho a unas otras reales, muy distintas de los constructos nacionalistas, islamistas, orientalistas o coloniales, siempre atravesados por rasgos patriarcales. Siendo nuestro propósito crear espacios dialógicos equitativos que permitan establecer relaciones de sororidad y trabajar conjuntamente para las aspiraciones compartidas de libertad, igualdad, dignidad y paz.

26. Incluyendo Women in Black, la antimilitarista New Profile, la rama israelí de WILPF, NOGA feminist Journal o Machsom Watch.

27. Lanzado el 9 de julio 2005, el llamamiento a Boicot, Desinversión y Sanciones contra Israel fue firmado por las organizaciones feministas palestinas más representativas: Union of Palestinian Women's Committee (UPWC); la Palestinian Federation of Women's Action Committees (PFWAC); la Union of Women's Work Committees (UWWC); Palestinian Women's Struggle Committees; Jerusalem Center for Women; Palestinian Working Women Society for Development (PWWSD); Women's Affairs Technical Committee de Ramallah y Gaza (WATC); el Women's Studies Center con su biblioteca feminista en Jerusalén Este (WSC); Women's Center for Legal Aid and Counseling (WCLAC).

28. En este sentido es muy conocida la labor de CODEPINK en Estados Unidos. La organización internacional WILPF también se adhirió al llamamiento BDS. 


\section{Referencias bibliográficas}

ABDo, Nahla. «Gender and Politics under the Palestinian Authority». Journal of Palestine Studies 2. 28 (1998-1999): 38. 15 junio 2015.

Ahmed-Gosh, Huma. «Dilemmas of Islamic and Secular Feminists and Feminisms». Journal of International Women's Studies 9.3 (2008): 99-116.

AL-AzmeH, Aziz. Islam s and Modernities, London: Verso, 1993.

AL'SANAH_RiYA. Who appointed the Palestinian minister of education? Al Arabi. 8 diciembre 2014. 15 junio 2015.

Álvarez-Ossorio, Ignacio. El miedo a la paz. De la Guerra de los Seis Días a la Segunda Intifada. Madrid. Catarata, 2001.

Amoros, Celia. «Feminismo y multiculturalismo». Teoría feminista de la Ilustración a la globalización, De los debates sobre el género al multiculuturalismo. Ed. Celia Amoros y Ana De Miguel. Madrid: Minerva, 2007: 217-264.

BADRAN, Margot. «Gender Activism: Feminists and Islamists in Egypt». En Moghadam, Valentine (ed.), Identity Politics and Women: Cultural Reassertions and Feminisms in International Perspective. Boulder: Westview Press, 1994.

BENHABIB, Seyla. Las reivindicaciones de la cultura. Igualdad y diversidad en la era global. Buenos Aires: Katz, 2006.

Brownmiller, Susan. Against our will, Men, Women and Rape. New York: Fawcett Book, 1993.

BUENDÍA PÉREZ, Pedro. «Estado, religión y los derechos humanos en la sociedad civil árabe: una aproximación teórica en el marco de las revueltas árabes». Sociedad civil y contestación en Oriente Medio y Norte de África. Ed. Ignacio Álvarez-Ossorio. Barcelona: CIDOB, 2013: 137-157.

Consejo de Derechos Humanos de Naciones Unidas (CDDHH). Informe de la comisión internacional independiente de investigación sobre la República Árabe Siria (A/HRC/24/46). Naciones Unidas, 2013.

Consejo Nacional Palestino. Declaration of Independence. 1988. 15 junio 2015.

DESRUES, Thierry. «El islamismo en el mundo árabe. Interpretaciones de algunas trayectorias políticas». Revista Internacional de Sociología 1.67 (2009): 9-28.

Euro-Mediterranean Human Rights Network (EMHRN). Violence against Women, Bleeding Wound in the Syrian Conflict, Copenhaguen: EMHRN, 2013.

Euro-Mediterranean Human Rights Network (EMHRN). Les droits des femmes palestiniennes dans les relationes UE-Israel et UE-Autorité Palestinienne. Copenhaguen: EMHRN, 2014.

FEMENías, María Luisa. El género del multiculturalismo. Buenos Aires: Bernal. 2013.

FEMENíAs, María Luisa. «El feminismo poscolonial y sus límites». Teoría feminista de la Ilustración a la globalización, De los debates sobre el género al multiculuturalismo. Ed. Celia Amoros y Ana De Miguel. Madrid: Minerva, 2007: 155-213. 
Giacaman, Rita, Jad, Islah y Johnson, Penny. «For the Common good? Gender and Social Citizenship in Palestine». Middle East Report 198 (1996).

GRESH, Alain. «Pour en finir (vraiment) avec le terrorismo». Le Monde Diplomatique, abril 2015.

Hammami, Reem. "Women, the Hijab and the Intifada». Middle East Report 164/165 (1990): 24-28+71+78.

International Institute for Strategic Studies. Armed Conflicts Database. 25 julio 2015.

JACOBY, Amanda Tami. «Gendered Nationalism and Palestinian Citizenship: Reconceptualizing the Role of Women in State Building», YCICC Working Paper 18 (1996). 15 de junio 2015.

JAD, Islah. «Islamist women of Hamas, Between feminism and nacionalism». Revue des mondes musulmans et de la Méditerranée 128 (2010). 25 junio 2015.

JAD, Islah. «Feminism between secularism and islamism: the case of Palestine (West Bank and Gaza). A conflicts Forum monograph». 2010. 25 junio 2015.

KANDiYoty, Denyz (ed.), Women, Islam and the State. Philadpelhi: Temple University Press, 1991.

KePEL, Gilles. La Yihad. Expansión y declive del islamismo. Barcelona: Península, 2001.

KutTAB, Eileen y Penny Johnson. «Where Have All the Women (and Men) gone? Reflections on Gender and the Second Palestinian Intifada». Feminist Review 61 (2001): 21-43.

LAGARDE, Marcela. El Feminismo en mi vida. Hitos, claves y topías. Madrid: Horas y Horas, 2014.

Lombardi, Clark B. «Constitutional Provisions Making Sharia «A» or «The» Chief Source of Legislation: Where Did They Come From? What Do They Mean? Do They Matter?» American University International Law Review 28, 3 (2013): 733-774.

LuDsIN, Hallie. Women and the draft Constitution of Palestine. Ramallah: Women's Centre for Legal Aid and Counselling, 2011.

MASSAD, Joseph. «Conceiving the masculine. Gender and Palestinian nationalism». Middle East Journal 49.3 (1995): 467-483.

MelHEM, Ahmad. «Palestinian activists press Abbas to outlaw honor crimes», Palestine Pulse, 12 de marzo 2014. 25 junio 2015.

Mir-Hosseini, Ziba. Islam and Gender: the Religious Debate in Contemporary Iran. London: I. B. Tauris, 1999.

MOGHISSI, Haydeh. Feminism and Islamic Fundamentalis, The limits of postmodern analysis. London/NewYork: Zed Books, 1999.

Moghadam, Valentine. «Islamic Feminisms and its Discontents: Toward a Resolution of the Debate». Signs 27.4 (2002):1135-1171. 
MOJAB, Shahrzad. «Islamic feminism: Alternative or contradiction?» Fireweed 47 (1995): 18-25.

Mozzafari, Mehdi. «What is Islamism? History and Definition of a Concept». Totalitarian Movements and Political Religions 8 (1) (2007): 17-33.

MuHiar MuÑumer, Hanady, «Las mujeres palestinas como objetivo de la ecuación demográfica», Segregados y recluidos. Los palestinos y las amenazas a su seguridad. Ed. Rafal Escudero. Madrid: Catarata, 2008.

NUÑO, Laura. «Violencia y deshumanización de las mujeres: la gran sombra en la protección internacional de los Derechos Humanos. Violencia de Género, una cuestión de Derechos Humanos. Ed. Ángela Figueruelo y otras. Granada: Comares, 2013.

Palestinian Central Bureau of Statistics. International Women's Day 2013. 15 julio 2015.http://www.pcbs.gov.ps/site/512/default.aspx? tabID=512\&lang=en\&Ite $\mathrm{mID}=725 \& \mathrm{mid}=3172 \&$ wversion=Staging.

PRATT, Nicola y Sophie Richter-Devroe. "Critically Examining UNSCR 1325 on Women, Peace and Security». International Feminist Journal of Politics 13.4 (2011): 489-503.

PRATT, Nicola y Sophie Richter-Devroe. Women, peace and security: new conceptual challenges and opportunities, Policiy Brief, Oslo: NOREF, 2013.

Richter-DeVroe, Sophie.«Palestinian Women's Everyday Resistance: Between Normality and Normalisation», Journal of International Women's Studies 12.2 (2011).

RICHTER-DEVROE, Sophie. «UNSCR 1325: Strengthening or Disciplining Women's Peace activism?» E-International Relations, diciembre 2012. 25 junio 2015.

SAGHAL, Gita y Nira Yuval-Davis. «Introduction: Fundamentalism, Multiculturalism and Women in Britain». Refusing Holy Orders: Women and Fundamentalism in Britain. Eds. Gita Sahgal y Nira Yuval-Davis. London: Virago, 1992.

Shaloub-KeVorkian, Nadera. Militarization and Violence against Women in Conflict Zones in the Middle East: A Palestinian Case Study. Cambridge: Cambridge University Press, 2009.

Shaloub-KeVorkian, Nadera, Ihmoud, Sarah y Suhad Dahir-Nashif. «Violencia sexual y colonialismo israelí». Viento Sur (2015). 15 junio 2015.

SHARONI, Simona, «Gender and Conflict Transformation in Israel/Palestine». Journal of International Women's Studies 13.4 (2012): 112-128.

Shlaim, Avi. The Iron Wall, Israel and the Arab World. London: Penguin Books, 2001.

THILL, Magali. «La mujer en los procesos de desarrollo y las revoluciones árabes». Sociedad civil en Oriente medio y Norte de África. Ed. Ignacio Álvarez Ossorio. Barcelona: CIDOB, 2103: 83-109. 
UN-Women. We just keep silent. Gender based violence among Syrian refugees in the Kurdistan Regionof Iraq. New York: United Nations, 2015.

Women Centre for Legal Aid and Counceling (WCLAC) y Geneva Centre for the Democratic Control of Armed Forces (DCAF). Palestinian Women and Penal Law, Policy Brief, Ramallah and Geneva, 2012.

World Bank, Checkpoints and Barriers: Searching for Livelihoods in the West Bank and Gaza. Gender Dimensions of Economic Collapse. World Bank, 2010. 